\title{
ASSESSMENT OF BUCKLING BEHAVIOUR ON AN FPSO DECK PANEL
}

\author{
Ozgur Ozguc \\ Istanbul Technical University \\ Department of Naval Architecture and Ocean Engineering, TURKEY
}

\begin{abstract}
Stiffened plates are the main structural building block in ship and offshore hulls and their structural response subject to loads is a topic of significant practical interest in ship and offshore structural design. To investigate the structural capacity for design and evaluation purposes, it is becoming an efficient and reliable practice to carry out non-linear finite element (FE) analysis. The present study is to assess the buckling strength of a stiffened deck panel on an FPSO vessel using the nonlinear finite element code ADVANCE ABAQUS, where imperfection sensitivity work is also accounted for. The cases studied correspond to in-plane bi-axial compression in the two orthogonal directions. The findings are compared with the DNVGL PULS (Panel Ultimate Limit State) buckling code for the stiffened panels. It is found that the strength values from the ADVANCE ABAQUS and DNVGL PULS code are very close. The results and insights developed from the present work are discussed in detail.
\end{abstract}

Keywords: buckling strength,imperfection sensitivity,nonlinear finite element analysis,FPSO unit,deck panel

\section{INTRODUCTION}

A typical ship and an offshore structure can be considered as an assemblage of continuous stiffened plates with equally spaced longitudinal stiffeners of approximately the same size. In order to analyse the ship's ultimate strength, the ultimate strength of the stiffened panels must be taken into account.

Since the overall failure of a ship or offshore hull is normally governed by buckling and plastic collapse of the deck, the bottom and the side shell stiffened plates, it is important to accurately calculate the ultimate strength of the stiffened panels in the deck, bottom and side shell in order to achieve a more advanced structural design of the ship.
Buckling is caused by in-plane stresses exceeding the buckling stability of the structure, causing local yield and permanent deformation of the structure. The buckling capacity is a property of the plate, depending on the stiffener spacing and the thickness.

Ship and offshore structures have been investigated by nonlinear finite element analysis in a large number of research works concerning ultimate strength and ultimate limit state (ULS) aspects. These studies have been utilised for plates, stiffened plates and three cargo holds in mid-ship areas [1]. Estimates of the ultimate strength of continuous plates were studied and developed by a simplified method that proposes formulae with more accurate predictions of the 
ultimate strength compared to NFEM results [7]. Assessment of the ultimate strength for unstiffened plates surrounded by supporting members under combined uniaxial/biaxial compressive loads and lateral pressures has been performed based on a series of benchmark studies on the methods [19]. For rectangular plates under biaxial loadings the elastoplastic buckling behaviour has also been studied [25]. The one-bay plate models from a $1 / 2+1+1 / 2$ bay continuous plate were investigated by Paik and Seo $[20,21]$ to reveal the fact that the ultimate strength of unstiffened plate under biaxial compressive loads was significantly influenced by rotational restraint under lateral pressure actions. A new method to analyse the geometric nonlinear behaviour of plates was developed, in which large elastic deflection or post-buckling of plates with partially restrained rotation and the torsional rigidity condition was applied [18].

Regarding the stiffened panel assessment, results were obtained in order to continuously develop improved methods for accurate and efficient prediction of the ultimate strength. To estimate the ultimate strength, some direct methods were proposed by Caldwell [2] and Mansour et al. [12] and a simplified method (Smith's method and the idealised structural unit method, ISUM) was later widely applied for analysis of hull girders under longitudinal bending loads only. By applying the mentioned methods to the analysis, results were rapidly obtained, but the accuracy depends on the average stress-strain relationship of individual structural members. The simplified method was developed [28] for evaluation of the collapse strength for hatch covers with a folding type and a side-sliding type of bulk carrier [16, 17]. The ALPS/ULSAP method was used to determine the ultimate limit state of a stiffened panel under uniaxial or biaxial compression and lateral pressures, and the results were compared to the ANSYS nonlinear finite element analysis. Related to the parameter effects on the collapse behaviour of stiffened panels, a shaped model with two $(1+1)$ full bays was studied by FEM. In addition to the ultimate strength of the plates, nonlinear FE software was used to analyse a two half bays plus one full bay $(1 / 2+1+1 / 2$ bay $)$ model in the longitudinal direction by Zhang and Khan [30] and Fujikubo et al. [8]. The influence of the stiffener's geometry and boundary conditions on the ultimate strength of stiffened panels under a combined thrust acting load including 3 bays, $1 / 2+1+1 / 2$ bays, $1+1$ bays and 1 bay, were analysed by $\mathrm{Xu}$ and Guedes Soares [27].

Ozguc et al. [14] developed new simple design equations for predicting the ultimate compressive strength of stiffened plates with initial imperfections in the form of weldinginduced residual stresses, and geometric deflections were developed in the study. To perform ANSYS elastic-plastic buckling analyses, a non-linear finite element method was employed, where a wide range of typical ship panel geometries from 60 different models was accounted for. The reduction factors of the ultimate strength were produced from the results of the 60 ANSYS inelastic finite element analyses. The accuracy of the proposed equations was validated by the experimental results. Comparisons indicated that the adopted method had sufficient accuracy for practical applications in ship design.

$\mathrm{Xu}$ et al. [26] investigated the influence of the lateral pressure and stiffener type on the collapse behaviours of steel stiffened panels using FE (finite element) analysis. Based on the numerical results, the empirical expressions were derived for the ultimate strength assessment of stiffened panels under combined in-plane axial compression and different levels of lateral pressure. The regression formulae only included the plate slenderness ratio and column (stiffener) slenderness ratio. Hence, to consider the influence of the stiffener type, the databases of sample points were separately grouped for various cross-sections in the regression process.

Kim et al. [10] carried out a comprehensive technical review on existing empirical formulations that predicted the ultimate limit state (ULS) of a stiffened panel under longitudinal compression. A detailed investigation on the lower range value of $\lambda$ was conducted using an ANSYS nonlinear finite element method (NLFEM)-based numerical simulation. A total of 10,500 cases were modelled using ANSYS numerical simulation by considering relevant size changes in the plate thickness, web thickness, flange thickness, height of web, and breadth of flange. In the case of an initial imperfection, only the average level of initial deflection to the plate and initial distortion to the stiffener elements were considered, while the residual stress due to welding was not considered. A detailed procedure including the selection of reliable scenarios, finite element (FE) modelling, FE analysis, and sensitivity analysis results, was also documented. The outcome obtained could be useful for understanding the ultimate compressive strength behaviour of a stiffened panel. Moreover, the applicability of the existing empirical formulations could also be assessed from the statistical analysis results.

Lee et al. [11] applied the ultimate limit states as the structural design criteria of a box girder crane. For this purpose, a reference box girder crane structure which was originally designed and constructed based on the allowable working stress criteria and still in operation was selected. The structure was then redesigned applying the ultimate limit state criteria, where other types of limit states such as serviceability limit states and fatigue limit states were also considered. A nonlinear finite element method was applied to analyse the progressive collapse behaviour of the structure until and after the ultimate limit state was reached. While the ultimate strength or maximum load-carrying capacity of the structure has never been realised as far as the allowable working stress based design method was applied, this study started by identifying it by the nonlinear finite element method.

Tekgoz et al. [24] analysed the effect of different finite element models on the ultimate strength assessment of stiffened plates, where the effect of the element size, and type, boundary conditions, shape of initial imperfection, thickness and net sectional configurations were accounted for. Four different finite element models and different structural configurations were compared to the solution described by the Common Structural Rules (CSR). Zhang and Jiang [29] 
developed a simple method for the ultimate strength analysis of square plates under combined longitudinal and transverse compressive stresses. The method was fully validated with the results of a systematic non-linear FE analysis. They also compared the methods from the industry standards BS5400 and DIN18800. Analysis examples were also provided in the paper for reference and discussion.

Oksina et al. [13] applied the idealised structural unit method (ISUM) for collapse analysis of large structures. The evaluation of the maximum load-carrying capacity of structures is an essential issue in determining their safety. Only if the prediction of the ultimate strength is ensured can their probability of survival in extreme load conditions be estimated. Particularly for safe dimensioning of ship structures, the determination of the structural strength against buckling and yielding is required by Common Structural Rules (CSR).

Shi et al. [22] evaluated the ultimate strength of stiffened panels under compressive loads by numerical simulations, for comparison with tests done to investigate the influence on the ultimate strength of varying the pit location, pit diameter and pit depth. The validated model was used for a numerical study on the influence of pitting on the residual ultimate strength of stiffened panels by a series of non-linear finite element analyses. The parameters of the pit position, diameter, number, depth, and corroded volume loss were investigated for the stiffened panels subjected to axial compressive load with initial deformations. It was found that the pits would induce the buckling failure of stiffened panels. All parameters were discussed to understand the significant influence on the residual ultimate strength of the pitting-corroded stiffened panel. Further, a formula was derived by introducing the reduction of plate slenderness and column slenderness.

Do et al. [6] applied the finite element method (FEM) and developed it to solve a complicated problem accurately. In particular, with the help of aid tool and software, as well as the nonlinear finite element method (NFEM), the ultimate strength of their large model was improved significantly and accurately. They investigated the ultimate stiffened panel strength in the cargo hold areas for a very larger ore carrier built in China.

The buckling strength assessment of a deck of a doublehull oil tanker was performed by Ozguc [15] using the nonlinear finite element code ADVANCE ABAQUS [9, 31]. Comparisons were carried out with the Det Norske Veritas (DNVGL) PULS (Panel Ultimate Limit State) buckling code [23] for the stiffened panels, DNVGL Classification Notes (CN) No. 30.1 [3] and the DNVGL Ship Rules [4]. The case studied corresponds to axial compression. Two levels of imperfection tolerances were analysed, in accordance with the specifications in the DNVGL Instruction to Surveyors (IS) [5] and the DNVGL Classification Notes No. 30.1 [3]. Both "as built" and DNVGL Rule [4] "net" dimensions were calculated.

The present work is to perform the buckling strength assessment of a stiffened deck panel on an FPSO vessel using the nonlinear finite element code ADVANCE ABAQUS, where an imperfection sensitivity work is also accounted for. The cases studied correspond to in-plane bi-axial compression in the two orthogonal directions. The findings are compared with the DNVGL PULS (Panel Ultimate Limit State) buckling code for the stiffened panels. It is found that the strength values from ADVANCE ABAQUS and DNVGL PULS code are very close.

This study determines that the quality and accuracy of the non-linear FE analysis results are highly dependent on the user's skills and the analysis procedures used for ship-shaped offshore FPSO vessels, where the deck structure is exposed to mostly buckling failure, which can be a good reference for the safety estimation.

Further, the buckling resistance of a deck depends on the plate thickness and the size and spacing of the supporting stringers. The results produced from the present work can inform the safe design of FPSO facilities.

\section{THE FINITE ELEMENT MODEL FOR ANALYSIS}

Typical stiffened panels are used in offshore structures through a comparison with non-linear finite element analyses. The main particulars of the panel are taken from the deck structure of an FPSO platform, and it has the dimensions (measured between girders) given in Table 1.

Tab. 1 Main scantling for analysed deck panel

\begin{tabular}{|l|c|}
\hline Stiffener length & $2500 \mathrm{~mm}$ \\
\hline Stiffener spacing & $500 \mathrm{~mm}$ \\
\hline Number of stiffeners & 24 \\
\hline Plate thickness & $9 \mathrm{~mm}$ \\
\hline Stiffener height (including flange thickness) & $160 \mathrm{~mm}$ \\
\hline Web thickness & $12 \mathrm{~mm}$ \\
\hline Flange width & $100 \mathrm{~mm}$ \\
\hline Flange thickness & $12 \mathrm{~mm}$ \\
\hline Profile type & Angle \\
\hline
\end{tabular}

The number of stiffeners has been reduced to eight in the finite element model to keep its size down and enhance its manageability. This should have only minor implications for the analysis results, since the number of stiffeners is still high. The latter is confirmed by the PULS elastic buckling calculation, which shows that the elastic buckling shape has a half-wave length in the order of the stiffener spacing in the transverse direction. To reduce the uncertainties introduced through boundary conditions, the finite element model has been extended by a half-frame spacing at each end, resulting in a model length of twice the stiffener length.

The strain hardening effect together with a bi-linear stressstrain curve is shown in Fig. 1. The Cowper-Symonds rate enhancement formula is used to consider the effect of the strain rate on the material properties as given in Eqs. (1)-(3), which are shown in Fig. 1 and Fig. 2. The material parameters are shown in Table 2. 
Tab. 2 The material properties

\begin{tabular}{|c|c|}
\hline Young's modulus, $\mathrm{E}\left[\mathrm{N} / \mathrm{mm}^{2}\right]$ & 206000 \\
\hline Poisson ratio, $v$ & 0.30 \\
\hline Material yield stress $\left[\mathrm{N} / \mathrm{mm}^{2}\right]$ & 235 \\
\hline Strain hardening parameter, $\mathrm{ET}\left[\mathrm{N} / \mathrm{mm}^{2}\right]$ & 1000 \\
\hline Strain rate $(\mathrm{C})$ & 40.4 \\
\hline Strain rate $(\mathrm{P})$ & 5.0 \\
\hline
\end{tabular}

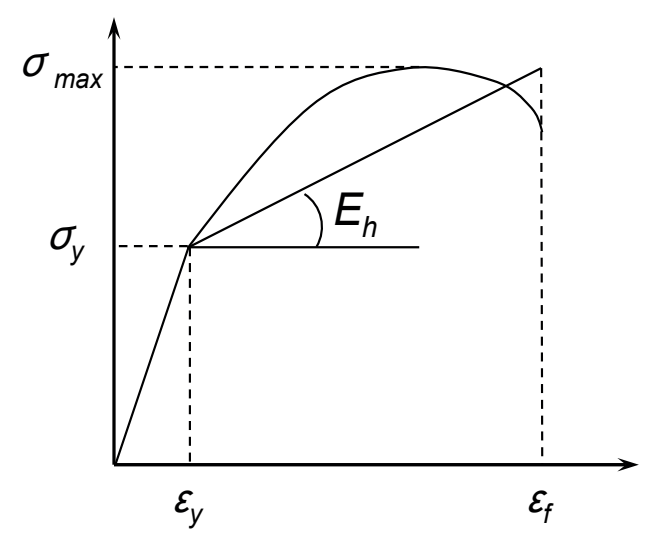

Fig. 1. Stress-strain curve for bi-linear material

$$
\begin{gathered}
\sigma_{p}=\sigma_{y}+\frac{E E_{h}}{E-E_{h}} \varepsilon_{p} \\
E_{h}=\frac{\sigma_{\max }-\sigma_{y}}{\varepsilon_{f}-\varepsilon_{y}}
\end{gathered}
$$

$\sigma_{y}=$ Yield stress

$E_{h}=$ Hardening modulus

$\sigma_{p}, \varepsilon_{p}=$ Plastic stress \& plastic strain

$E=$ Young's modulus

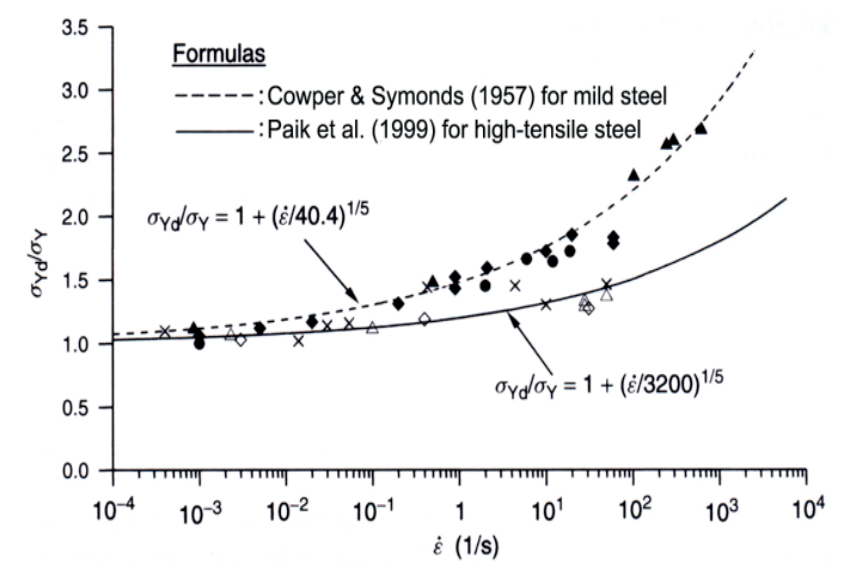

Fig. 2. Strain rate effect

$$
\frac{\sigma_{y d}}{\sigma_{y}}=1+\left\{\frac{\varepsilon}{D}\right\}^{1 / q}
$$

It is noted that for mild steel grade $\mathrm{D}=40.4$ and $\mathrm{q}=5$ are used.

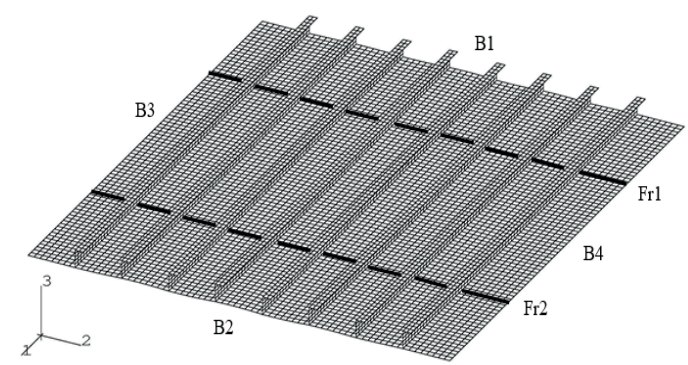

Fig. 3. The finite element model with labelled boundaries

Boundary conditions are imposed on the edges and lines indicated in Fig. 3. Symmetry conditions are given on edges B1 and B2. This might represent a constraint on the deformation of the plate and on the web and flange of the stiffener, but experience from other similar analyses indicates that this has little impact on the results. Edge B2 is fixed in the 1-direction.

Edges B3 and B4 are fixed in the lateral direction and in the rotation about the 1-axis. The latter is to keep the panel from collapsing in one of the outermost plate fields. Edge B4 is fixed in the 2-direction, while edge B3 is free to move in this direction but with the edge constrained to remain straight.

Lines labelled Fr1 and Fr2 correspond to the positions of transverse frames or girders. At these locations the panel is fixed in the lateral direction. Furthermore, the stiffeners are constrained to remain vertical in order to simulate the presence of frames/girders.

\section{GEOMETRIC IMPERFECTIONS}

Steel structures are typically fabricated by flame cutting and welding, and thus initial imperfections in the form of initial distortions and residual stresses may develop and will reduce the collapse capacity. These initial imperfections should therefore be included in the structural design as parameters of influence.

When local heating is applied to structural steels, the heated part will expand, but because of adjacent cold parts it will be subjected to compressive stress and distortion. When the heated part is cooled down, it will be locally shrunk rather than revert to its initial shape and thus now be subjected to tensile stress. Approximate methods based on the insights from measurements are usually adopted for design purposes because of the complexity of the phenomena involved, while some efforts have been made to estimate the initial imperfections theoretically or numerically. In this study, the tolerances level on the plate out-of-flatness and stiffener 
out-of-straightness are taken from the DNVGL Classification Notes No. 30.1 [3] as follows in Fig. 4.

$$
\begin{aligned}
& \delta_{\mathrm{P} 0}=0.01 \mathrm{~s} \\
& \delta_{\mathrm{S} 0}=0.0015 \mathrm{~L} \\
& \delta_{\mathrm{T} 0}=0.0015 \mathrm{~L}
\end{aligned}
$$

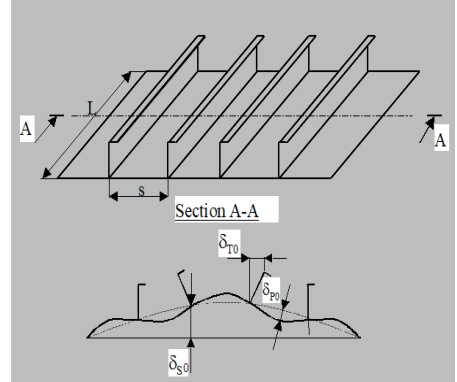

Fig. 4.. The imperfection parameters used in this study

In addition to the base tolerance level, six other tolerance levels have been analysed as shown in Table 3, in order to study the imperfection sensitivity of the panel strength.

Tab. 3. Imperfection tolerance levels

\begin{tabular}{|l|c|c|c|}
\hline \multicolumn{1}{|c|}{ Identification } & $\delta_{\mathrm{P} 0}$ & $\delta_{\mathrm{SO}}$ & $\delta_{\mathrm{T} 0}$ \\
\hline Level 1 & $0.005 \mathrm{~s}$ & 0 & $0.0015 \mathrm{~L}$ \\
\hline Level 2 & $0.01 \mathrm{~s}$ & 0 & $0.0015 \mathrm{~L}$ \\
\hline Level 3 (base level) & $0.01 \mathrm{~s}$ & $0.0015 \mathrm{~L}$ & $0.0015 \mathrm{~L}$ \\
\hline Level 4 & $0.01 \mathrm{~s}$ & $0.003 \mathrm{~L}$ & $0.003 \mathrm{~L}$ \\
\hline Level 5 & $0.02 \mathrm{~s}$ & 0 & $0.0015 \mathrm{~L}$ \\
\hline Level 6 & $0.02 \mathrm{~s}$ & $0.0015 \mathrm{~L}$ & $0.0015 \mathrm{~L}$ \\
\hline Level 7 & $0.02 \mathrm{~s}$ & $0.003 \mathrm{~L}$ & $0.003 \mathrm{~L}$ \\
\hline
\end{tabular}

The shape of the imperfections is generally composed of a local component (plate out-of-flatness and stiffener flange out-of-straightness) and a global component (stiffener outof-straightness). The local component is itself composed from a subset of the elastic buckling modes for the panel for the specific load combination at hand. Ten of these buckling modes are shown in Fig. 5 below. Strictly, this procedure requires that the deformation pattern in the buckling modes excludes lateral deflection of the stiffeners, a requirement that is not entirely met in this case. However, to distribute out-ofplane deformations in the shape of the lowest eigenmodes, also involving some minor lateral deflections of stiffeners, is always conservative. Analyses are performed for three different local imperfection shapes defined in Table 4.

Tab. 4. Composition of the three local imperfection shapes used in the analyses

\begin{tabular}{|c|c|c|c|c|c|c|c|c|c|c|}
\hline & \multicolumn{7}{|c|}{ Weight factors for the ten lowest buckling modes } \\
in the local imperfections \\
\hline Mode & 1 & 2 & 3 & 4 & 5 & 6 & 7 & 8 & 9 & 10 \\
\hline Local 1 & 10 & 1 & 1 & 1 & 1 & 1 & 1 & 1 & 1 & 1 \\
\hline Local 2 & 1 & 1 & 1 & 1 & 1 & 1 & 1 & 1 & 1 & 1 \\
\hline Local 3 & 1 & 0 & 0 & 0 & 0 & 0 & 0 & 0 & 0 & 0 \\
\hline
\end{tabular}

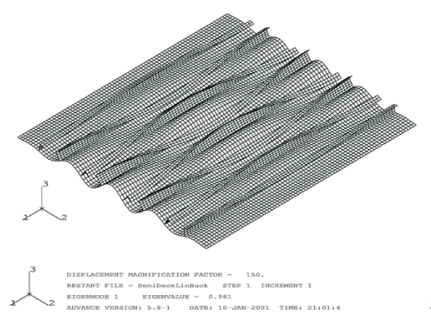

Eigenmode 1

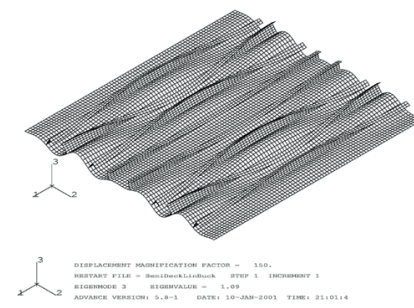

Eigenmode 3

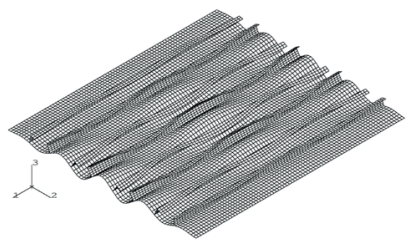

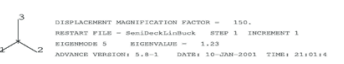

Eigenmode 5

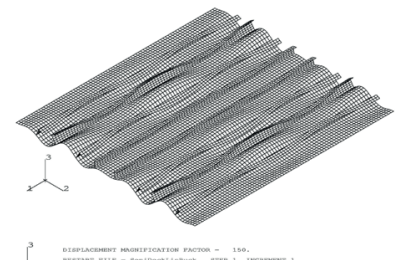

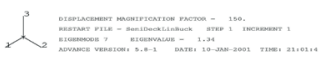

Eigenmode 7

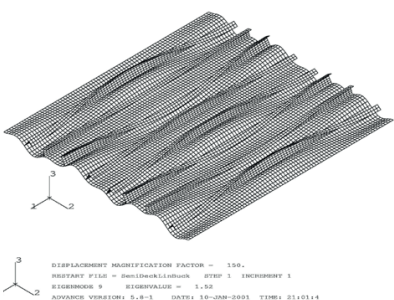

Eigenmode 9

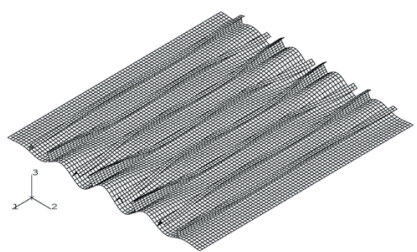

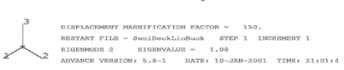

Eigenmode 2

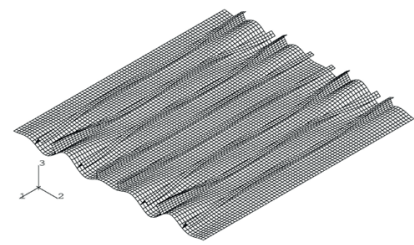

2.

Eigenmode 4

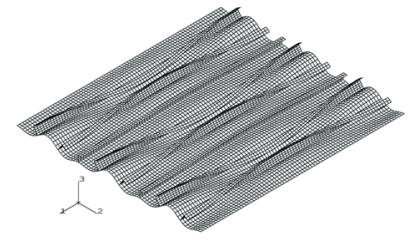

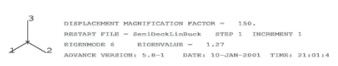

Eigenmode 6

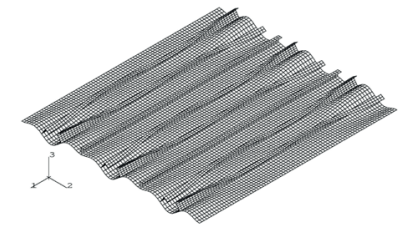

C.

Eigenmode 8

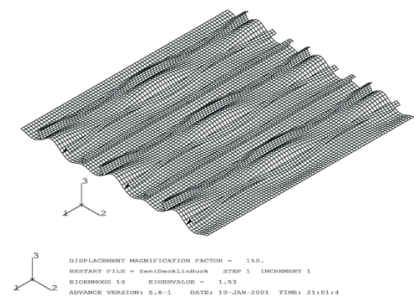

Eigenmode 10
Fig. 5. The ten lowest buckling modes for the deck panel

\section{GLOBAL IMPERFECTION PATTERN}

Global stiffener imperfections are specified in a half sine wave pattern along the stiffener length, and two different patterns in the transverse direction: an alternating short wave pattern with linearly varying displacements between each stiffener as illustrated in Fig. 6 (Global 1), and a half sine wave variation as illustrated in Fig. 7 (Global 2). These half-wave patterns span the total panel width of eight stiffeners, and the three-stiffener model is only used for illustration purposes. 
The first of these transverse patterns is expected to yield the most conservative results in cases where large transverse compressive loads are present, since it closely resembles the lowest global eigenmodes in PULS.

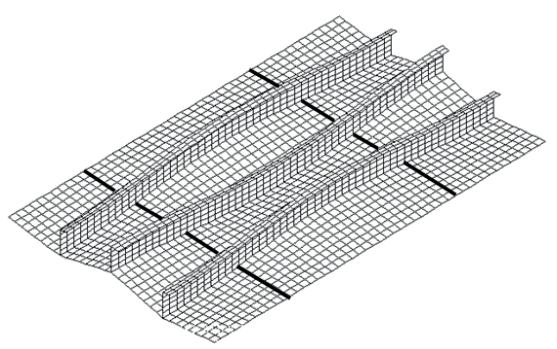

Fig. 6. Linearly varying alternating stiffener imperfection mode (Global 1)

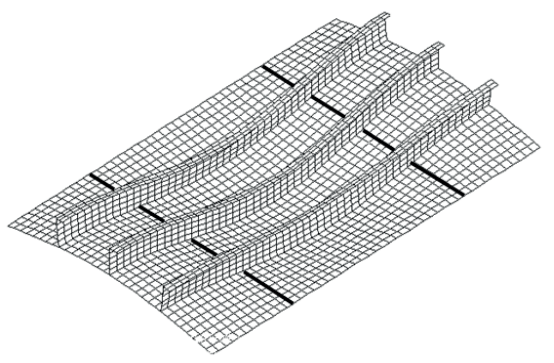

Fig. 7. Sine varying stiffener imperfection mode (Global 2)

Tab. 5. Definition of the analysed imperfection combinations

\begin{tabular}{|c|c|c|c|}
\hline Identification & Local shape & Global shape & Tolerance level \\
\hline Case 1 & Local 1 & - & Level 2 \\
\hline Case 2 & Local 1 & Global 1 & Level 3 (base level) \\
\hline Case 3 & Local 1 & Global 1 & Level 4 \\
\hline Case 4 & Local 1 & Global 2 & Level 2 \\
\hline Case 5 & Local 3 & - & Level 1 \\
\hline Case 6 & Local 3 & - & Level 2 \\
\hline Case 7 & Local 3 & - & Level 5 \\
\hline Case 8 & Local 2 & - & Level 2 \\
\hline Case 9 & Local 1 & - & Level 5 \\
\hline Case 10 & Local 1 & Global 1 & Level 6 \\
\hline Case 11 & Local 1 & Global 1 & Level 7 \\
\hline Case 12 & Local 3 & Global 1 & Level 2 \\
\hline
\end{tabular}

Twelve different combinations of global imperfection shapes, local imperfection shapes and tolerance levels have been analysed, and are defined in Table 5. A comparison of the results from Case 1 - Case 3 and Case 9 - Case 11 will give information about the sensitivity to global stiffener imperfections for the given geometry and load combination. However, the behaviour observed here may be restricted to the selected imperfection shape.

Furthermore, a pairwise comparison of Case 1 - Case 9, Case 2 - Case 10 and Case 3 - Case 11 will give information about the sensitivity to plate / torsional imperfections. The same will be the case by comparing Case 5 to Case 7, but then with another imperfection shape as a basis.

Case 2 and Case 4 differ only in the shape of the global stiffener imperfection, and differences in results must be related to this difference. The imperfection shape is also the only thing separating Case 2 from Case 12 and Case 1 from Case 6 and Case 8, but for these the difference is in the shape of the local imperfection.

\section{LOAD APPLICATION}

All analyses are performed in load control, i.e. the nonlinear solution is found by incrementing the magnitude of the applied forces proportionally. All edges are constrained to remain straight, and the model is loaded by applying a resultant nodal force consistent with the design stresses to one node on each of the two loaded edges. This is illustrated in Fig. 8.

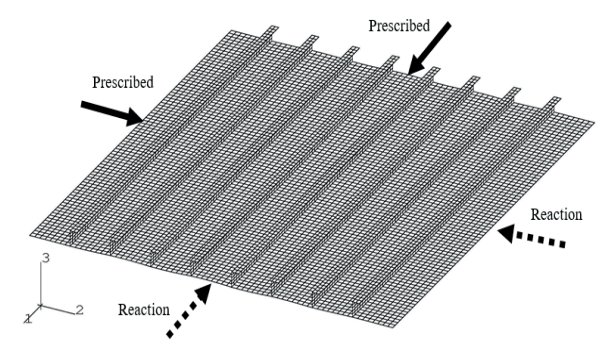

Fig. 8. Illustration of how loads are applied to the FE model

The design loads for the panel are as follows:

$\sigma_{1}=100 \mathrm{MPa}$ (axial stress),

$\sigma_{2}=60 \mathrm{MPa}$ (transverse stress),

$\tau_{12}=5 \mathrm{MPa}$ (in-plane shear stress)

For simplicity, the shear loads have been disregarded in the finite element analyses, since the load component is small and is expected to have little impact on the results.

\section{FINITE ELEMENT RESULTS}

All results will be given as a load proportionality factor (LPF) with the design loads as the reference state. A summary of the results from the ADVANCE ABAQUS analyses is given in Table 6 . They show that the effects of the global stiffener imperfections are small, and reduce the capacity by the order of $2.5 \%$ for the variations in magnitude analysed here. The sensitivity to plate imperfections is larger, but still the difference introduced by quadrupling its magnitude is below $15 \%$. A doubling of the plate imperfection magnitude reduces the capacity by the order of 8-10\%. Note that the local imperfection scaling also includes some marginal stiffener imperfections. Comparing Case 1 with Case 8, the effect of the different imperfection shape appears to be of the same magnitude as the variations in the size of the imperfections. For this panel and load combination, a local imperfection in the shape of the first elastic buckling mode appears to produce the most conservative capacity estimate. Case 12 thus represents a lower capacity bound for the given tolerance level. However, the difference between Case 12 and the other 
cases representing the same tolerance level (Case 1, Case 2, Case 4, Case 6 and Case 12) is very small.

Tab. 6. Calculated load proportionality factors associated with collapse of the panel for Case 1 to Case 12

\begin{tabular}{|c|c|c|}
\hline Identification & LPF ADVANCE & Case 1 / Case 12 \\
\hline Case 1 & 1.341 & 1.033 \\
\hline Case 2 (Basis case) & 1.324 & 1.019 \\
\hline Case 3 & 1.305 & 1.033 \\
\hline Case 4 & 1.339 & 1.063 \\
\hline Case 5 & 1.379 & 1.014 \\
\hline Case 6 & 1.315 & 0.927 \\
\hline Case 7 & 1.199 & 1.089 \\
\hline Case 8 & 1.414 & 0.959 \\
\hline Case 9 & 1.242 & 0.951 \\
\hline Case 10 & 1.233 & 0.938 \\
\hline Case 11 & 1.216 & 1.000 \\
\hline Case 12 & 1.299 & \\
\hline
\end{tabular}

Based on the results in Table 6, it can be concluded that an LPF in the area of 1.3 is a good representation of the strength of the panel for imperfection tolerances on and around the requirements in DNVGL CN30.1 [3]. The calculated failure mode is collapse of a plate field between two stiffeners, and is identical for all the analysed cases. This failure mode is characteristic of panels loaded with a large transverse stress. Figs. 9 to 11 show contour plots of the stresses and plastic strains at the ultimate load level, which illustrates the failure mode.

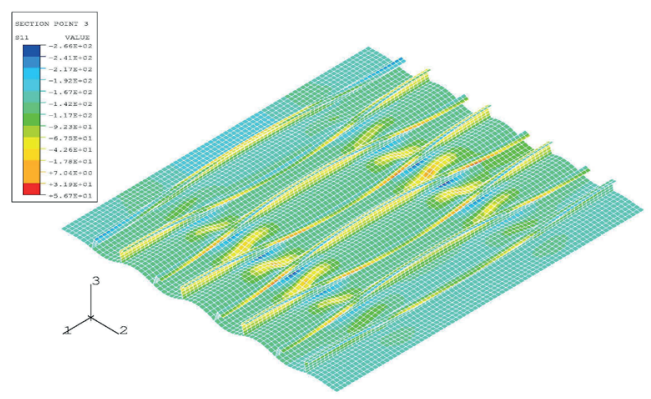

Fig. 9. Axial membrane stress in the panel at the ultimate load level

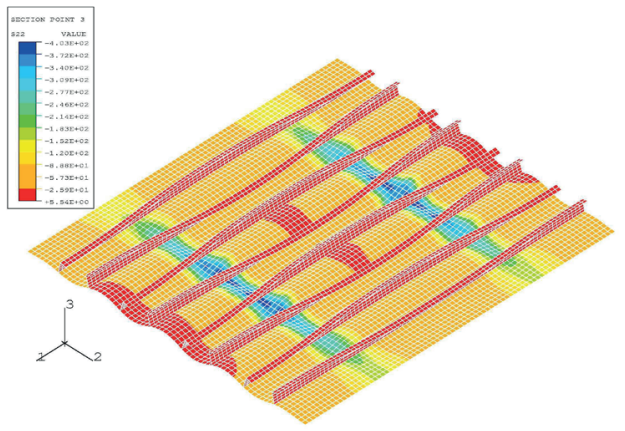

Fig. 10. Transverse membrane stress in the panel at the ultimate load level

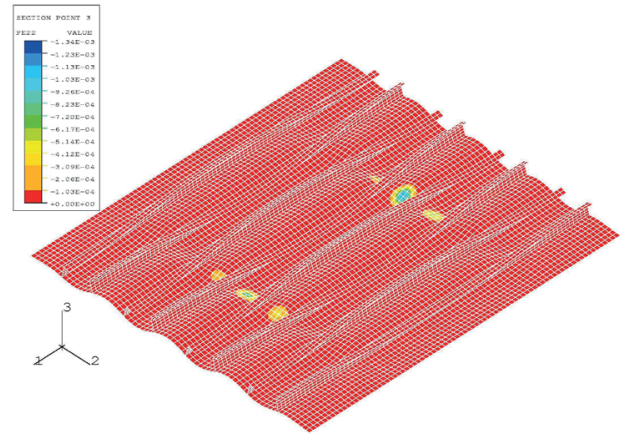

Fig. 11. Membrane yield zones in the panel at the ultimate load level

\section{COMPARISON WITH PULS CODE}

The findings show that the DNVGL PULS code produces capacity estimates in very good agreement with the ABAQUS finite element analysis results based on the initial imperfection levels and shapes described in the paper, where the results from DNVGL PULS are well on the conservative side. The strength predictions are considered valid for imperfection levels relevant for ship and offshore structures in the "as-built" condition. For the example geometry and load combination, DNVGL PULS estimates an ultimate strength load proportionality factor of 1.33 , whereas the ADVANCE ABAQUS results are in the range of $1.32-1.35$ for the DNVGL CN30.1 tolerance level.

Clearly, this result accords very well with the finite element results. The DNVGL PULS code predicted nearly the same strength for the original design load combination with an additional shear stress of $\tau_{12}=5 \mathrm{MPa}$.

\section{CONCLUDING REMARKS}

The finite element code ADVANCE ABAQUS has been used in a nonlinear buckling analysis of a stiffened deck panel on an FPSO platform. The PULS code computerised buckling code is employed to compare the capacity estimates obtained from nonlinear finite element analysis by ABAQUS. A single bi-axial load combination has been investigated. The imperfection tolerances given in DNVGL CN30.1 have been used as the basis for the analyses, but several other combinations with both larger and smaller tolerances have been analysed. In total, twelve different shapes and magnitudes of geometric imperfections have been analysed. The results show that the PULS code produces capacity estimates which are in very good agreement with the nonlinear finite element results. Given in terms of the load proportionality factor on the design loads, the DNVGL PULS code estimates a capacity of 1.33, whereas the ADVANCE ABAQUS results are in the range of 1.32-1.35 for the CN30.1 tolerance level, depending on the shape of the imperfections. For this specific example, the results also indicate that the DNVGL PULS code results are valid for tolerance levels exceeding the DNVGL CN30.1 
tolerance. Direct application of geometrical non-linear plate theory is the main concept in the new Panel Ultimate Limit State (PULS) stiffened panel models recently recognised by DNVGL as part of the new rules and standards for ships and offshore constructions. The focus is on assessment of the ultimate capacity limit, rather than the more traditional elastic buckling limit. The method is streamlined for rules based on modern ultimate limit state design principles. The models are validated against non-linear FE analyses.

\section{REFERENCES}

1. Amlashi H., Moan T. (2009): Ultimate strength analysis of a bulk carrier hull girder under alternate hold loading condition, Part 2: Stress distribution in the double bottom and simplified approaches. Marine Structures, 22 (3), 522-544.

2. Caldwell J. B. (1965): Ultimate longitudinal strength. Trans. Royal Inst. Nav. Arch., 107, 411-430.

3. DNV GL Classification Notes (2017): Buckling strength analyses, CN 30.1 .

4. DNV GL Rules for Classification (2018): Hull structural design ships with length 100 meters and above, Part 3 Chapter 1.

5. DNV GL Rules (2015): Hull survey - workmanship standard, DNV Instructions to Surveyors No. I-B3.3.

6. Do H. C., Jiang W., Jin J., Chen X. (2013): An investigation of ultimate strength for VLOC stiffened panel structure. Modern Transportation, 2(2), 23-38.

7. Fujikubo M., Harada M., Yao T., Khedmati M. R., Yanagihara D. (2005): Estimation of ultimate strength of continuous stiffened panel under combined transverse thrust and lateral pressure, Part 2: Continuous stiffened panel. Marine Structures, 18, 411-427.

8. Fujikubo M., Yao T., Khedmati M. R., Harada M., Yanagihara D. (2005): Estimation of ultimate strength of continuous stiffened panel under combined transverse thrust and lateral pressure, Part 1: Continuous plate. Marine Structures, 18, 383-410.

9. Karlson H., Sorensen I. (2012): ABAQUS/Standard User's Manual.

10. Kim D. K., Lim H. L., Yu S. Y. (2018): A technical review on ultimate strength prediction of stiffened panels in axial compression. Ocean Engineering, 170(15), 392-406.

11. Lee D. H., Kim S. J., Lee M. S., Paik J. K. (2019): Ultimate limit state based design versus allowable working stress based design for box girder crane structures. Thin-Walled Structures, 134, 491-507.

12. Mansour A. E., Liu D., Paulling J. R. (2008): Strength of ships and ocean structures. Principles of Naval Architecture Series (Society of Naval Architects and Marine Engineers (US). Jersey City, N.J.: Society of Naval Architects and Marine Engineers.

13. Oksina A., Lindemann T., Kaeding P., Fujikubo M. (2016): Idealized structural unit method: A review of the current formulation. International Conference on Offshore Mechanics and Arctic Engineering, Volume 9: Prof. Norman Jones Honoring Symposium on Impact Engineering; Prof. Yukio Ueda Honoring Symposium on Idealized Nonlinear Mechanics for Welding and Strength of Structures.

14. Ozguc O., Das P. K., Barltrop N. (2007): The new simple design equations for the ultimate compressive strength of imperfect stiffened plates. Ocean Engineering, 34(7), 970-986.

15. Ozguc O. (2018): Estimation of buckling response of the deck panel in axial compression. Polish Maritime Research, 25, No. 100, 98-105.

16. Paik J., Kim B., Seo J. (2008a): Methods for ultimate limit state assessment of ships and ship-shaped offshore structures: Part I-Unstiffened plates. Ocean Engineering, 35(2), 261-270.

17. Paik J., Kim B., Seo J. (2008b): Methods for ultimate limit state assessment of ships and ship-shaped offshore structures: Part II-Stiffened plates. Ocean Engineering, 35(2), 261-270.

18. Paik J., Kim B., Seo J. (2008c): Methods for ultimate limit state assessment of ships and ship-shaped offshore structures: Part III -Hull girders. Ocean Engineering, 35 (2), 281-286.

19. Paik J. K., Kim D. K., Lee H., Shim Y. L. (2012): A method for analyzing elastic large deflection behavior of perfect and imperfect plates with partially rotation-restrained edges. Journal of Offshore Mechanics and Arctic Engineering, 134.

20. Paik J. K., Seo J. K. (2009a): Nonlinear finite element method models for ultimate strength analysis of steel stiffened-plate structures under combined biaxial compression and lateral pressure actions-Part I: Plate elements. Thin-Walled Structures, 47(8-9), 1008-1017.

21. Paik J. K., Seo J. K. (2009b): Nonlinear finite element method models for ultimate strength analysis of steel stiffened-plate structures under combined biaxial compression and lateral pressure actions-Part II: Stiffened panels. Thin-Walled Structures, 47(8-9), 998-1007. 
22. Shi X. H., Zhang J., Soares C. G. (2018): Numerical assessment of experiments on the ultimate strength of stiffened panels with pitting corrosion under compression. Thin-Walled Structures, 133, 52-70.

23. Steen E., Byklum E., Vilming K. G. (2010): PULS verification manual - PULS Version 2.0.

24. Tekgoz M., Garbatov Y., Soares C. G. (2012): Ultimate strength assessment accounting for the effect of finite element modelling. Maritime Engineering and Technology, 59-74.

25. Wang G., Sun H., Peng H., Uemori R. (2009): Buckling and ultimate strength of plates with openings. Ships and Offshore Structures, 4(1), 43-53.

26. Xu M. C., Song Z. J., Zhang B. W., Pan J. (2018): Empirical formula for predicting ultimate strength of stiffened panel of ship structure under combined longitudinal compression and lateral loads. Ocean Engineering, 162, 161-175.

27. Xu C. M., Guedes Soares C. (2012): Numerical assessment of experiments on the ultimate strength of stiffened panels. Engineering Structures, 45, 460-471.

28. Yao T. (2003): Hull girder strength. Marine Structures, 16(1), 1-13.

29. Zhang S., Jiang L. A. (2015): Method for ultimate strength assessment of plates in combined stresses. International Conference on Offshore Mechanics and Arctic Engineering, $3,145-167$.

30. Zhang S., Khan I. (2009): Buckling and ultimate capability of plates and stiffened panels in axial compression. Marine Structures, 22(4), 791-808.

31. ABAQUS Analysis User's Guide (2017): Unstable Collapse and Post-buckling Analysis.

\section{CONTACT WITH THE AUTHOR}

Ozgur Ozguc

e-mail:ozguco@yahoo.com.sg

Istanbul Technical University, Dept. of Naval Architecture and Ocean Eng., Maslak, 34469 Istanbul,

TURKEY 